\title{
PERCEIVED EFFECTIVENESS OF INFLUENCE TACTICS IN THE UNITED STATES AND CHINA
}

\author{
Ping Ping Fu \\ Chinese University of Hong Kong \\ Gary Yukl* \\ State University of New York at Albany
}

\begin{abstract}
A cross-cultural study was conducted with managers from the United States and China to investigate differences in influence behavior. Managers rated the effectiveness of different influence tactics for several representative situations. Significant differences were found between American and Chinese managers in a large, multinational company with facilities in both countries. The results were replicated for a second sample consisting of several organizations in each country. Rational persuasion and exchange were rated as more effective by American managers than by Chinese managers. Coalition tactics, upward appeals, and gifts were rated more effective by Chinese managers than by American managers. The influence tactics accurately predicted nationality for $94 \%$ of the respondents.
\end{abstract}

\section{INTRODUCTION}

Managers need to exercise influence in an appropriate way in order to sell their ideas, gain acceptance of their policies, and motivate others to implement their decisions (Cohen \& Bradford, 1991; Yukl, 1998). The difficulties of exercising influence are increased when dealing with people from different cultures. Cultural values can profoundly affect the attitudes, behavior, and performance of individuals (Adler, 1983; Hofstede, 1983; House, Wright, \& Aditya, 1997; Schwartz, 1994). The ability to understand cultural differences and exercise influence in cross-cultural interpersonal networks is now regarded as an essential competency of the "global" manager (Smith \& Peterson, 1988). Managers will be more effective if they have

\footnotetext{
* Direct all correspondence to: Gary Yukl, Management Department, State University of New York at Albany, Albany, NY 12222; e-mail: g.yukl@albany.edu.
}

Leadership Quarterly, 11(2), 251-266.

Copyright (C) 2000 by Elsevier Science Inc.

All rights of reproduction in any form reserved.

ISSN: 1048-9843 
strong cultural awareness and know how to influence people with a different cultural background.

With the rapid rise of China as a political and economic power, understanding cross-cultural differences between that nation and the United States has acquired a special significance. As more and more American companies do business in China, it is essential to understand how the cultural differences shape the attitudes and behavior of Chinese managers. One type of behavior likely to reflect cultural differences is the use of proactive influence tactics. The purpose of our exploratory study was to determine if there are important differences in the way Chinese and American managers exert influence in business organizations.

\section{Cultural Differences Between the United States and China}

China and the United States still differ greatly with regard to their economic systems, political systems, social values, and laws, despite the substantial changes that have occurred in China during recent years (Tse, Francis, \& Walls, 1994). Cross-cultural research has shown that, compared to American managers, Chinese managers have higher values for uncertainty avoidance, power distance, collectivism, femininity, and long-term orientation (Fu \& Taber, 1998; Hofstede, 1993; Hofstede \& Bond, 1988; Ralston, Gustafson, Cheung, \& Terpstra, 1993; Smith, Dugan, \& Trompenaars, 1996). Some unique cultural beliefs and traditions have also been identified for the Chinese people (Bond, 1991; Brunner \& Wang, 1988; Hui \& Graen, 1997; Hwang, 1987; Ralston, Gustafson, Elsacs, Cheung, \& Terpstra, 1992). Examples include "guan-xi" (relatedness or connections among sets of individuals) and "mian-zi" (maintaining face by keeping the respect of others and showing respect for them). American managers are more individualistic, masculine, shortterm oriented, egalitarian, and comfortable with uncertainty. Strong cultural traditions in the United States include an emphasis on competition, pragmatism, democracy, and individual rights.

\section{Multiple Determinants of Manager Behavior}

Like invisible jet streams in the skies that determine the course of a storm, deep cultural undercurrents shape our lives in subtle but highly consistent ways (Hall, 1981). Managers who grow up in a culture are likely to internalize the dominant cultural values, and these values will influence their attitudes and behavior in ways that may not be conscious (Adler, 1997). In addition, cultural values are reflected in societal norms about the way people relate to each other. These norms specify acceptable forms of interpersonal behavior, including influence tactics. In some cases, the norms may be formalized as societal laws limiting the use of power to influence the decisions and actions of others.

Regardless of whether managers internalize cultural values about influence behavior, most managers will conform to social norms about this behavior. One reason is that deviation from societal norms may result in diminished respect and social pressure from other members of the organization. Another reason for conformity with social norms is that use of unacceptable influence tactics may result in a 
negative affective reaction by the target person, and this reaction would undermine the effectiveness of the behavior.

National culture is only one of many determinants of a manager's behavior (Bass, 1990; House et al., 1997; Yukl, 1998). Other determinants include the manager's traits and skills, the manager's power and authority, organization rules and policies, the organization climate, and the nature of the task. The cultural and noncultural determinants of behavior are not always congruent. Some situational variables may have parallel effects across national cultures, but other situational variables may interact with national culture in complex ways. When there is an interaction, crosscultural differences may be found in some situations but not others. Thus, the effects of national culture on behavior should be examined in a variety of situations.

\section{Cross-Cultural Research on Leadership by Chinese Managers}

To date, most cross-cultural research on leadership has involved aspects of leadership behavior such as supportive or maintenance-oriented leadership, directive or production-oriented leadership, contingent reward, contingent punishment, and transformational or charismatic leadership. Several of the studies included Chinese managers, but, in most cases, these managers lived in Hong Kong, Taiwan, or Singapore rather than in mainland China (e.g., Dorfman \& Howell, 1988; Dorfman, Howell, Hibino, Lee, Tate, \& Bautista, 1997; Gerstner \& Day, 1994; Smith, Misumi, Tayeb, Peterson, \& Bond, 1989).

In some studies, the primary basis for cross-cultural comparison was the conceptualization of leadership behavior, as defined by factor structures or leadership prototypes. In other studies, mean scores were compared across countries to determine how much each type of leadership behavior was used in each country. A few studies examined cross-cultural differences in the relationship of leadership behavior to outcomes such as subordinate satisfaction, motivation, and performance. The crosscultural research on leadership has found both similarities and differences among countries (Den Hartog et al., 1999; Dorfman, 1996; House et al., 1997).

Even though most of the leadership behaviors used in the cross-cultural research involve some attempt to influence subordinates, no direct correspondence has been established between these leadership behaviors and proactive influence tactics like the ones described below. Moreover, most proactive influence tactics are used with peers and superiors as well as with subordinates. Thus, the leadership research is not very helpful for extrapolating likely cross-cultural differences in the perceived effectiveness of influence tactics or their frequency of use.

\section{Research on Influence Tactics}

The influence behavior of managers has been studied with a variety of research methods, including survey questionnaires, scenarios, experimental simulations, and analysis of influence incidents obtained with interviews or open-ended questionnaires. A number of distinct influence tactics have been identified in this research (e.g., Kipnis, Schmidt, \& Wilkinson, 1980; Schriesheim \& Hinkin, 1990; Yukl \& Falbe, 1990; Yukl \& Tracey, 1992). The most commonly identified influence tactics include rational persuasion, exchange, ingratiation, pressure, coalition, and upward 
appeals. Support for the construct validity of these six tactics has been found in factor analyses of survey questionnaires used with American managers in the United States (e.g., Kipnis et al., 1980; Schriesheim \& Hinkin, 1990; Yukl \& Falbe, 1990) and Chinese managers in Taiwan (Schmidt \& Yeh, 1992).

Previous research has found that other aspects of the influence situation, besides national culture, also affect the influence behavior of managers. Examples of these situational determinants include the nature of the influence objective, the direction of influence, and the agent's authority and position power in relation to the target (Erez, Rim, \& Keider, 1986; Kipnis et al., 1980; Yukl \& Falbe, 1990; Yukl, Falbe, \& Youn, 1993; Yukl, Guinan, \& Sottolano, 1995; Yukl \& Tracey, 1992). Only a few studies have attempted to compare different countries with regard to how often different influence tactics are used by managers in large organizations. Researchers have compared the United States to other Asian countries/regions such as Japan (Hirokawa \& Miyahara, 1986; Rao, Hashimoto, \& Rao, 1997), Taiwan (Schmidt \& Yeh, 1992), and Hong Kong (Schermerhorn \& Bond, 1991). These studies provide evidence that influence behavior is affected by national culture, but they did not directly compare American managers in the United States to Chinese managers in mainland China.

\section{Likely Chinese-American Differences in Influence Behavior}

Differences in cultural values for Chinese and American managers are likely to be reflected in their perception of tactic effectiveness and their use of each type of tactic. However, the implications of cultural values are more evident for some influence tactics than for others. Four tactics that seemed likely to reflect cultural differences are rational persuasion, coalition, upward appeals, and gifts.

To exercise influence and resolve differences, American managers will prefer to use tactics that involve directly confronting others with rational arguments, factual evidence, and suggested solutions (Ting-Toomey, 1985). It is a traditional way to resolve conflicts and solve problems, and it is consistent with the high level of assertiveness, pragmatic short-term orientation, and moderately low power distance in the United States. Studies of American managers indicate that a strong form of rational persuasion is one of the most effective influence tactics, regardless of the direction of influence (Yukl, Kim, \& Falbe, 1996; Yukl \& Tracey, 1992). Thus, we would expect American managers to view rational persuasion as highly effective and to use this tactic frequently in their influence attempts. Even though rational persuasion is a flexible tactic that can be useful in any culture, Chinese managers are likely to use it less than American managers, because it can provoke overt disagreement, which is considered highly undesirable.

American managers prefer to use direct, confrontational tactics for most types of requests, and they are reluctant to invest the time and effort required to enlist the help of other people, unless it is clearly necessary to influence the target person (Yukl, Falbe, \& Youn, 1993). In contrast, the strong collective orientation and uncertainty avoidance values in China encourage Chinese managers to use indirect forms of influence that involve the assistance of a third party (Bond, 1991). For a difficult or controversial request, indirect forms of influence provide a way to avoid 
losing face and damaging guan-xi. Coalition partners can also help to convey the message that a request or proposal is consistent with the desires and needs of others besides the agent. Thus, it seems likely that coalition tactics and upward appeals will be considered more effective by Chinese managers than by American managers.

Chinese managers emphasize interpersonal relationships more than American managers, and these relationships provide an important basis for influence. In China, gifts are a useful way to build and strengthen relationships. Giving gifts is a common tradition, and it is consistent with the Chinese values of uncertainty avoidance, femininity, and long-term orientation. Small gifts are given to people with whom one has a formal work relationship as well as to people with whom one has a social relationship. Gifts are given on various occasions and for various purposes, including when one wants to ask the person for a favor. In the United States, it is often considered inappropriate (a "bribe") to give a gift when seeking a favor or making a controversial request. Even a small gift can create the appearance of a conflict of interest for the target person. Thus, gifts will be viewed much less favorably by American managers than by Chinese managers.

\section{Research Questions}

This study is the first in a program of related studies. The following questions were explored in this research (the first two are the primary ones):

1. Are some tactics considered more effective by Chinese managers than by American managers?

2. Are some tactics considered less effective by Chinese managers than by American managers?

3. Are the tactics considered most effective by American managers also the ones considered most effective by Chinese managers?

4. Are there any culturally-specific influence tactics used by Chinese managers but not by American managers?

5. How strong is the effect of national culture on perception of influence tactics (in relation to other situational and individual determinants)?

6. How well can the nationality of a manager be predicted from his or her pattern of ratings on tactic effectiveness?

7. How useful are fixed-response scenarios for studying cross-cultural differences?

\section{METHOD}

We selected a modified scenario method for our research, because it would allow us to assess general cross-cultural differences in perception of tactic effectiveness for a variety of contexts. Even though perceptions are not equivalent to behavior, we assumed that perceived effectiveness of a tactic would be closely related to how much the tactic is used. As a supplementary research method, subsamples of the Chinese and American managers were interviewed to collect incidents describing actual influence attempts made by these managers. 


\section{Samples}

Our research was conducted with two different samples from each country. The first sample consisted of American and Chinese managers from the same multinational corporation, which was selected in order to hold constant the company culture and type of managerial position. The sample included 41 managers from a manufacturing facility in the United States and 42 managers from a similar facility in China. Although separated by the Pacific Ocean, the two factories use the same equipment, produce the same products, and are organized in the same way. The managers in the two facilities hold similar responsibilities and duties. To avoid cultural contamination, we only included managers who were born and raised in the focal country. All eligible managers who had a minimum of three direct subordinates were invited to participate in the study by the head of the division. The participation rate was $95 \%$ of the eligible managers. The scenario questionnaire was administered by the first author at the company facilities in the United States and China. She also interviewed 15 of the Chinese managers and 15 of the American managers prior to giving them the scenarios to rate. The managers were asked to describe past influence incidents with subordinates, peers, and superiors.

The use of parallel facilities in a multinational company helps to control for extraneous effects of other situational variables such as organization type, size, ownership, and structure, but reliance on a single company would restrict the generalizability of the findings. To avoid this obvious limitation, a second sample was obtained from both countries. The second sample consisted of mid- and lowerlevel managers in both small and large manufacturing companies. It was a convenience sample obtained through personal contacts. In the United States, the data were collected from 42 managers in four companies located in two northeastern states. The Chinese data were collected from 46 managers in six state-owned companies, four in southern China and two in a coastal city in northern China.

Demographic information was collected for all of the managers, and the combined samples were compared with regard to each demographic variable. The average age was 40 years for the American managers and 35 years for the Chinese managers, and this difference was significant $(F=7.7, p<.01)$. The percentage of males was $77 \%$ for American managers and $70 \%$ for the Chinese managers, and this difference was not significant. The American managers had more (college) education than the Chinese managers $(F=17.2, p<.01)$. There was no significant difference between countries with regard to level of management or time in the company.

\section{Scenarios}

In psychological research, a "scenario" is a brief description of a situation that is used to assess respondent perceptions and reactions. Scenarios are commonly used to manipulate two or more independent variables in a systematic way. In this initial study, we did not use scenarios to manipulate situational variables, but only to assess respondent perceptions across a variety of influence situations that are typical for managers in large organizations.

Our scenarios incorporated three potentially relevant situational determinants of tactic effectiveness: direction of influence (downward, lateral, upward), influence objective (task-related or personal benefit for agent), and personal relationship 
(professional colleague or close friend). The combinations of direction and objective were not random, but were instead based on common configurations found in earlier research with influence incidents (Yukl, Falbe, and Youn, 1993). We included interpersonal relationship (i.e., friendship) between agent and target as a situational variable, because we suspected that it may affect perceptions about the feasibility of using various influence tactics. The agent has more referent power when there is a close friendship, and this provides an additional source of influence (French \& Raven, 1959; Yukl, 1998). However, a close friendship may also make the agent more wary about using impersonal or hard tactics (e.g., strong pressure) that could undermine the relationship (Hinkin \& Schriesheim, 1990).

Each scenario included a brief description of the authority relationship between the agent and target person to establish the direction of influence. The target was described as a subordinate, peer, or boss of the agent. Common names were used for the agent and target, who were identified as males because most of the managers in the study were males. Our seven scenarios included three with a direct subordinate as the target, two with a lateral peer as the target, and two with a boss as the target. Each scenario specified the agent's influence objective, and it was more likely to be task-related (five scenarios) than a personal benefit (two scenarios). The scenario also specified if there was a close friendship between the agent and the target person, but a professional relationship between agent and target was more common (five scenarios) than a close friendship (two scenarios). Following are examples of three scenarios, one in each direction. The examples do not have the names that we used for the agent and target person, which were different in each country.

\section{Scenario 1 (downward; professional relationship; task-related objective)}

The manager wants to assign a subordinate to a task that is only distantly related to his job. The subordinate is reluctant to take on the task, because his current job responsibilities are already overwhelming. How effective would each tactic be to influence the subordinate to do the task?

\section{Scenario 2 (lateral; professional relationship; task-related objective)}

The manager's department has three more days to fulfill a large order from an important client, but the amount of work remaining requires at least five days. The only way the manager can do it is to borrow a few workers from the manager of another department. How effective would each tactic be to influence the other manager to provide the worker?

\section{Scenario 3 (upward; professional relationship; personal-benefit objective)}

There is an opportunity for a promotion to a higher position in the organization. The manager would like to be selected for the position, but two other candidates are also being considered. The decision will be made by the vice president for human resources, who is the manager's boss. How effective would each tactic be for influencing the vice president to promote the manager?

\section{Influence Tactics}

Attached to each scenario was a list of specific tactics likely to be relevant for that scenario. In this exploratory study, we attempted to include a wide variety of 
relevant tactics in the scenarios. Examples include: rational persuasion, exchange, coalition, upward appeals, ingratiation, pressure, consultation, inspirational appeals, and personal appeals. Many of the tactic items were similar to items used in the Profile of Organizational Influence Strategies (Kipnis et al., 1980; Schriesheim \& Hinkin, 1990) and the Influence Behavior Questionnaire (Yukl \& Tracey, 1992). Roughly half of the tactic items were tailored to the scenario to clarify the meaning for respondents in that context.

Not all tactics were represented in every scenario, and some scenarios had more than one item from the same tactic category. The selection of tactics for a scenario was based in part on previous research about the types of influence tactics most likely to be used in a particular direction for a particular objective. However, because most of the research on influence tactics has been done in the United States, we also used focus groups of Chinese nationals to identify additional tactics that may be especially relevant for China. For some scenarios, the focus groups identified specific tactics that did not correspond very closely to any of the tactic categories already represented. Two examples of these new tactic categories are the use of unconditional gifts prior to a request, and making the request in an informal setting outside of the workplace. Some examples of influence tactics used for Scenario 1 are as follows:

- Explain why the task is important for the department and organization (rational persuasion);

- Offer a financial incentive for doing the additional task (exchange);

- Get help in persuading him from one of his coworkers (coalition);

- Get someone with higher authority to tell him to do the task (upward appeal);

- Express confidence in his ability to accomplish the task successfully (ingratiation);

- Demand that he must do the task. (pressure).

Some examples of tactics used for Scenario 2 are as follows:

- Explain why the requested assistance is important for the organization (rational persuasion);

- Offer to do something for him in return for his assistance (exchange);

- Ask someone close to him to persuade him to provide assistance (coalition);

- Ask a superior with higher authority to help influence him (upward appeal);

- Compliment him about something he did before asking for assistance (ingratiation);

- Give him a small gift that he will like before making the request (gift).

Respondents were asked to rate how effective each tactic would be if used in an attempt to get the target person in the scenario to do what the agent wants. The 5-point rating scale had anchors for each response choice $(1=$ completely ineffective, $2=$ somewhat ineffective, $3=$ slightly effective, $4=$ moderately effective, 5 = very effective). Each scenario also contained an open-ended question 
asking the respondent to briefly describe any other ways to effectively deal with the situation.

Before using the scenarios in China, two bilingual persons familiar with behavioral literature translated them from English into Chinese. The Chinese version was back-translated into English by a Chinese American. Another bilingual person checked the back-translated English against the original English to make sure that the original questions were adequately conveyed in Chinese.

\section{RESULTS}

\section{Reliability of Measures}

Cross-cultural differences were evaluated primarily in terms of scale scores. Influence tactic items from the scenarios were initially assigned to tactic scales based on the results from factor analyses in previous survey research. This assignment of items to scales was also verified with a content analysis of the items. In the United States, 12 doctoral students were given a list of tactic definitions and asked to code each scenario item into one of the tactic categories (or to indicate that it did not fit well into any category). The same procedure was used with 15 Chinese graduate students for coding tactics in the Chinese-language version of the scenarios. An item was included in a scale only when at least $70 \%$ of the coders in each country agreed that it belonged in that scale.

The internal consistency of the tactic scales was assessed separately for the American and Chinese managers. In most attitude and behavior questionnaires, a scale consists of a set of similar items without any description of the context. In our scenarios, the wide variety of situations and examples is likely to reduce the consistency of rated effectiveness for the tactics. Nevertheless, internal consistency is still relevant for interpreting the meaning of the results. High internal consistency implies that the cross-cultural results obtained for a tactic are similar across situations. For a scale to be included in the comparative analysis, we required an alpha value of at least .60 for both nationalities. Alpha values for the seven retained tactics ranged from .61 to .84 for the United States sample and from .60 to .83 for the Chinese sample.

The pattern of correlations among scale scores was consistent with our assumption that the scales measure perception of distinct tactics. In the United States sample, none of the 21 correlations exceeded .60 and only three correlations exceeded .50. In the Chinese sample, only two of the 21 correlations exceeded .60 , and they both involved partially overlapping tactic categories (upward appeal correlated .64 with coalition; gifts correlated .65 with exchange). In summary, the scales did not appear to be confounded with each other or contaminated by strong response biases.

To evaluate whether we overlooked any relevant tactics in creating the scenarios, we examined the respondents' answers to the open-ended question attached to each scenario. Most of the tactics suggested by respondents were similar to ones already provided with the scenario. The added tactic was sometimes just a suggestion to use a combination of two or more of the listed tactics. 
Table 1. Means, Standard Deviations, and $F$-Tests for Sample 1

\begin{tabular}{lcccccccr}
\hline & \multicolumn{2}{c}{ Mean Scale Score } & & \multicolumn{3}{c}{ Standard Deviation } & & \\
\cline { 2 - 3 } Influence Tactic & $\begin{array}{c}\text { United States } \\
\text { of America }\end{array}$ & China & & $\begin{array}{c}\text { United States } \\
\text { of America }\end{array}$ & China & F & Eta $^{2}$ \\
\hline Rational persuasion & 4.23 & 3.36 & & 0.42 & 0.63 & $54.5^{\dagger}$ & .40 \\
Exchange & 3.62 & 2.71 & & 0.56 & 0.48 & $63.0^{\dagger}$ & .44 \\
Gifts/favors & 1.37 & 2.42 & & 0.54 & 0.79 & $48.5^{\dagger}$ & .38 \\
Coalition tactics & 2.16 & 2.75 & & 0.54 & 0.55 & $23.9^{\dagger}$ & .23 \\
Upward appeal & 2.27 & 2.64 & & 0.81 & 0.69 & $5.1^{*}$ & .06 \\
Ingratiation & 3.12 & 3.01 & & 0.54 & 0.63 & 0.8 & \\
Pressure & 2.12 & 2.22 & & 0.58 & 0.50 & 0.6 & \\
\hline
\end{tabular}

${ }^{*} p<.05$ for $F(d f=1,81){ }^{\dagger} p<.01$.

\section{Cross-Cultural Differences}

The effect of national culture on perception of influence tactics for Sample 1 was evaluated with a multivariate analysis of variance (MANOVA). Table 1 shows the scale means, standard deviations, and the univariate $F$-tests from the MANOVA. Compared with the Chinese managers, American managers gave significantly higher effectiveness ratings to rational persuasion and exchange. Compared with American managers, Chinese managers gave significantly higher ratings to coalition tactics, upward appeals, and gifts. There was no significant cross-cultural difference for pressure or ingratiation.

Even when a cross-cultural difference is statistically significant, it has little practical significance unless the effect size is substantial. The eta square values in Table 1 show the effect size for each tactic with a significant difference. Based on the guidelines recommended by Cohen (1988), the eta square values indicate that there was a large effect of national culture on rational persuasion, exchange, coalition tactics, and gifts, but only a relatively weak effect on upward appeals.

The analysis for Sample 2 was done in the same way. The results are shown in Table 2. The findings in Sample 1 were all replicated in Sample 2. The American managers gave relatively higher effectiveness ratings to rational persuasion and

Table 2. Means, Standard Deviations, and $F$-tests for Sample 2

\begin{tabular}{|c|c|c|c|c|c|c|}
\hline \multirow[b]{2}{*}{ Influence Tactic } & \multicolumn{2}{|c|}{ Mean Scale Score } & \multicolumn{2}{|c|}{ Standard Deviation } & \multirow[b]{2}{*}{$\mathrm{F}$} & \multirow[b]{2}{*}{$E t a^{2}$} \\
\hline & $\begin{array}{c}\text { United States } \\
\text { of America }\end{array}$ & China & $\begin{array}{c}\text { United States } \\
\text { of America }\end{array}$ & China & & \\
\hline Rational persuasion & 4.09 & 3.33 & 0.57 & 0.58 & $38.3^{\dagger}$ & .31 \\
\hline Exchange & 3.70 & 2.93 & 0.55 & 0.68 & $34.1^{\dagger}$ & .28 \\
\hline Gifts/favors & 1.46 & 2.62 & 0.62 & 0.93 & $45.8^{\dagger}$ & .35 \\
\hline Coalition tactics & 2.34 & 2.64 & 0.63 & 0.64 & $4.9 *$ & .05 \\
\hline Upward appeal & 2.38 & 2.74 & 0.77 & 0.75 & $5.0^{*}$ & .06 \\
\hline Ingratiation & 3.00 & 2.82 & 0.60 & 0.54 & 2.2 & \\
\hline Pressure & 2.31 & 2.09 & 0.71 & 0.54 & 2.9 & \\
\hline
\end{tabular}

$* p<.05$ for $F(d f=1,86) ;{ }^{\dagger} p<.01$. 
exchange, and the Chinese managers gave relatively higher ratings to coalition tactics, upward appeals, and gifts. As before, there was not a significant crosscultural difference for pressure or ingratiation. The effect sizes were smaller this time, perhaps because we used a convenience sample rather than a matched sample. Nevertheless, national culture still had a large effect on ratings of rational persuasion, exchange, and gifts.

\section{Supplementary Analyses for Scenarios}

An analysis of covariance was conducted for the combined sample to rule out the possibility that the cross-cultural results were caused by the extraneous effects of the demographic variables that were confounded with nationality. Controlling for the effects of demographic variables (e.g., age, education, gender) did not change the results substantially for any influence tactic. All the cross-cultural differences were still significant, although the effect size sometimes changed slightly.

Discriminant analysis was used with the combined sample to examine how well the proactive influence tactics collectively differentiated between the American and Chinese managers. This analysis takes into account the intercorrelation among some of the influence tactics. The discriminant analysis used the five influence tactics with significant cross-cultural differences. Prediction accuracy would be around $50 \%$ if managers were classified on a strictly random basis. In the discriminant analysis, national identity was correctly identified for $94 \%$ of the respondents, which is a high level of prediction accuracy.

\section{Results for Interviews}

Transcripts from the interviews with Chinese and American managers were examined to see if there was any information to help interpret the cross-cultural differences found in the scenarios. The interview results appeared to be consistent with the major findings in the scenario data. The American managers described more influence incidents involving direct forms of influence, such as rational persuasion, whereas the Chinese managers described more use of indirect tactics, such as coalition and upward appeals. However, there were not enough incidents for a quantitative test of cross-cultural differences in behavior.

One advantage of interviews is that they can provide insights about subtle differences in the way a particular type of tactic is used in each country. Descriptive research with American managers (Yukl, Falbe, \& Youn, 1993) indicates that they usually seek help from coalition partners or higher authorities only after a direct influence attempt with the target person has failed. Our interviews suggested that the Chinese managers were more likely than American managers to seek informal assistance from third parties for difficult, controversial requests before approaching the target person directly. This indirect approach may be an attempt to avoid situations of open disagreement, which can result in loss of face for both parties.

In China, when an influence attempt is not successful initially, and a coalition or upward appeal is used as a follow-up tactic, it seems less likely to be regarded as a hard tactic that will undermine the agent-target relationship. In the United 
States, upward appeals usually mean getting a superior to exert pressure on a peer or superior who is resisting the agent's request. The target person usually ends up feeling resentment toward the agent, and sometimes, also toward the superior. Having someone with higher authority resolve an emerging disagreement may be more consistent with Chinese values regarding power distance and respect for authority. The interviews revealed that an upward appeal may be initiated by the target person as well as by the agent. For example, in one incident, the target person claimed that he lacked the authority to grant the agent's request, but he asked the agent to talk to his boss and agreed to carry out the request if the boss approved it. Getting a superior to decide the issue provided an opportunity for both parties to save face.

\section{DISCUSSION}

Our study was the first to directly compare managers in the United States and mainland China with regard to perception of influence tactics. We found several significant cross-cultural differences. Rational persuasion and exchange were rated more effective by American managers than by Chinese managers. Coalition tactics, upward appeals, and gifts were rated more effective by Chinese managers than by American managers. There was no significant difference for pressure and ingratiation. This pattern of results cannot be attributed to a general bias in respondent ratings from one country.

\section{Interpretation of Results}

The results for rational persuasion, coalition, and upward appeals were consistent with known cross-cultural differences in values and traditions for the two countries. As noted earlier, rational persuasion is consistent with the preference of Americans for direct confrontation and use of reasoning to influence people and resolve differences in an organizational setting. Coalition tactics and upward appeals are consistent with the Chinese preference for using indirect approaches for difficult or controversial requests. Gifts are a cultural tradition for the Chinese, and they are used to strengthen relationships in the workplace.

The cross-cultural difference found for exchange tactics was not predicted clearly by cultural differences, and the reason for it is more speculative. In the United States, the high level of individualism and pragmatic interest in immediate effects may encourage the use of exchange tactics. Offering an incentive or explicit exchange is a direct, confrontational approach for gaining compliance with a difficult request, and this approach may be more consistent with American customs for resolving conflicts. In China, the importance of long-term relationships may make managers more ambivalent about the effectiveness of using exchange as a proactive influence tactic. It is more complicated in China to determine the appropriate form of exchange. When the target person is a friend, offering an impersonal exchange or the wrong incentive may cause one or both parties to lose face. When the target 
person is not a friend, but future interaction is expected, unconditional gifts and personal favors may be more effective than impersonal exchanges for building a cooperative relationship.

\section{Advantages and Limitations of the Study}

Although only an exploratory study, our research has several advantages or unique qualities in comparison with most previous cross-cultural studies. We used a matched sample from the same organization, and we included a replication sample to verify the results and increase external validity. Most previous studies did not report effect sizes, control for the possible effects of extraneous variables, or compute the overall prediction of nationality from manager behavior. Our study is not the first to use scenarios for cross-cultural research, but we had a larger number of scenarios representing a wider variety of typical influence situations. Our scenarios were pretested in focus groups to ensure that they were clear and meaningful, and to discover other relevant tactics that we may have overlooked.

Despite these advantages, our study also has some limitations. One limitation is that the scenarios measure only a respondent's perceptions about tactic effectiveness. It is possible that ratings of tactic effectiveness do not correspond closely to actual use of the tactic. Our confidence in the scenario results is bolstered by the supplementary interviews conducted with some of the managers, but there is still need for rigorous research on how often each tactic is actually used in various contexts by managers in each country.

Another limitation is that our scenarios were newly developed for this study, and it was not possible to ensure in advance that we would have internally consistent scales for every type of influence tactic that may be relevant. We found some evidence of interesting cross-cultural differences that we did not report because they involved tactic scales without strong internal consistency. For example, compared with the American managers, the Chinese managers gave higher effectiveness ratings to personal appeals and to requests made in an informal context (e.g., a restaurant or someone's home). The scenario questionnaire will be revised before it is used again to improve scale reliability, include more tactics, and counterbalance situational variables better within scenarios.

A third limitation is that we did not design the scenarios to assess the direct or moderating effects of the situational variables. However, the pattern of results for some tactics suggested the possibility of culture by situation interactions. Future research should be designed to assess likely interactions in a more systematic way.

Another limitation is the size and composition of our samples. The samples were relatively small for cross-cultural research on countries with vast numbers of managers. In addition, most of the respondents were from large manufacturing companies. The results may not generalize to managers in very small organizations, or to managers in other types of organizations (e.g., health care, service industries, retailing organizations, government agencies). Future research should include larger, more diverse samples, and it should examine possible interactions between national culture and type of organization. 
A final limitation shared by most cross-cultural studies is the tendency to focus on differences at the expense of similarities. Traditional statistical methods fail to provide a good method for assessing similarity in comparative studies. Nevertheless, a modest degree of similarity is evident between the Chinese and American managers in their relative ratings for the various tactics. For example, most of the managers from both countries viewed rational persuasion as a relatively effective tactic and pressure as an ineffective tactic. This similarity suggests that other determinants, besides cultural values, have strong effects that may transcend national boundaries. Thus, it is essential to appreciate the differences found in our study without translating them into simplistic, rigid stereotypes of Chinese and American managers. An objective for future research should be to develop a better understanding of the factors that determine both the similarities and differences in influence behavior across cultures.

\section{REFERENCES}

Adler, N. J. (1983). Cross-cultural management research: The ostrich and the trend. Academy of Management Review, 8(2), 226-232.

Adler, N. J. (1997). International dimensions of organizational behavior. Cincinnati, OH: South-Western College Publishing.

Bass, B. M. (1990). Handbook of leadership (3rd ed.). New York: Free Press.

Bond, M. H. (1991). Beyond the Chinese face. Hong Kong: Oxford University Press.

Brunner, J. A., \& Wang, Y. (1988). Chinese negotiating and the concept of face. Journal of International Consumer Marketing, 1, 27-43.

Cohen A. R., \& Bradford, D. (1991). Influence without authority. New York: Wiley.

Cohen, J. (1988). Statistical power analysis for the behavioral sciences (2nd ed.). Hillsdale, NJ: Lawrence Erlbaum Associates.

Den Hartog, D. N., House, R. J., Hanges, P. J., Ruiz-Quintanilla, S. A., Dorfman, P. W., and Associates. (1999). Culture specific and cross-culturally generalizable implicit leadership theories: Are the attributes of charismatic/transformational leadership universally endorsed? Leadership Quarterly, 10, 219-256.

Dorfman, P. W. (1996). International and cross-cultural leadership. In B. J. Punnett \& O. Shenkar (Eds.), Handbook of international management research (pp. 267-349). Cambridge, MA: Blackwell.

Dorfman, P. W., \& Howell, J. P. (1988). Dimensions of national culture and effective leadership patterns. Advances in International Comparative Management, 3, 127-150.

Dorfman, P. W., Howell, J. P., Hibino, S., Lee, J. K., Tate, U., \& Bautista, A. (1997). Leadership in Western and Asian countries: Commonalities and differences in effective leadership practices across cultures. Leadership Quarterly, 8, 233-274.

Erez, M., Rim, Y., \& Keider, I. (1986). The two sides of the tactics of influence: Agent vs. target. Journal of Occupational Psychology, 59, 25-39.

Gerstner, C. R., \& Day, D. V. (1994). Cross-cultural comparison of leadership prototypes. Leadership Quarterly, 5, 121-134.

French J., \& Raven, B. H. (1959). The bases of social power. In D. Cartwright (Ed.), Studies of social power(pp. 150-167). Ann Arbor, MI: Institute for Social Research.

Fu, P. P., \& Taber, T. (1998). National cultural similarities and differences: A comparison between U.S. and Chinese managers. Paper presented at the Southern Management Association meetings, New Orleans, LA. 
Hall, E. T. (1981). Beyond culture. New York: Bantam Doubleday Dell Publishing Group.

Hinkin, T. R., \& Schriesheim, C. A. (1990). Relationships between subordinate perceptions of supervisor influence tactics and attributed bases of supervisory power. Human Relations, 43, 221-237.

Hirokawa, G., \& Miyahara, A.. (1986). A comparison of influence strategies utilized by managers in American and Japanese organizations. Communication Quarterly, 34, 250-265.

Hofstede, G. (1983). National cultures in four dimensions: A research-based theory of cultural differences among nations. International Studies of Management and Organization, 13, $46-74$.

Hofstede, G. (1993). Cultural constraints in management theories. Academy of Management Executive, 7, 81-90.

Hofstede, G., \& Bond, M. H. (1988). The Confucian connection: From cultural roots to economic growth. Organizational Dynamics, 16, 4-21.

House, R. J., Wright, N. S., \& Aditya, R. N. (1997). Cross-cultural research on organizational leadership: A critical analysis and a proposed theory. In P. C. Earley \& M. Erez (Eds.), New perspectives on international/organizational psychology (pp.535-625). San Francisco: New Lexington Press.

Hui, C., \& Graen, G. (1997). Guanxi and professional leadership in contemporary SinoAmerican joint ventures in mainland China. Leadership Quarterly, 8, 451-465.

Hwang, K K. (1987). Face and favor: The Chinese power game. American Journal of Sociology, 92, 944-974.

Kipnis, D., Schmidt, S. M., \& Wilkinson, I. (1980). Intra-organizational influence tactics: Explorations in getting one's way. Journal of Applied Psychology, 65, 440-452.

Ralston, D. A., Gustafson, D. J., Cheung, F. M., \& Terpstra, R.H. (1993). Differences in managerial values: A study of U.S., Hong Kong and PRC managers. Journal of International Business Studies, 24, 249-275.

Ralston, D. A., Gustafson, D. J. Elsacs, P. M., Cheung, F. M., \& Terpstra, R. H. (1992). Eastern values: A comparison of managers in the United States, Hong Kong and the People's Republic of China. Journal of Applied Psychology, 77, 664-671.

Rao, A., Hashimoto, K., \& Rao, A. (1997). Universal and culturally specific aspects of managerial influence: A study of Japanese managers. Leadership Quarterly, 8, 295-312.

Schermerhorn, J. E., \& Bond, M. H. (1991). Upward and downward influence tactics in managerial networks: A comparative study of Hong Kong Chinese and Americans. Asia Pacific Journal of Management, 8, 147-158.

Schmidt, S. M., \& Yeh, R. H. (1992). The structure of leader influence: A cross national comparison. Journal of Cross-Cultural Psychology, 23, 251-262.

Schriesheim, C. A., \& Hinkin, T. R. (1990). Influence tactics used by subordinates: A theoretical and empirical analysis and refinement of the Kipnis, Schmidt, and Wilkinson subscales. Journal of Applied Psychology, 75, 246-257.

Schwartz, S. H. (1994). Beyond individualism-collectivism: New cultural dimensions of values. In U. Kim, H. C. Triandis, \& G. Yoon (Eds.), Individualism and collectivism (pp. 85-117). London: Sage.

Smith, P. B., Dugan, S., \& Trompenaars, F. (1996). National culture and the values of organizational employees: A 43-nation study. Journal of Cross-Cultural Psychology, 27, 231-264.

Smith, P. B., Misumi, J., Tayeb, M. H., Peterson, M., \& Bond, M. H. (1989). On the generality of leadership styles across cultures. Journal of Occupational Psychology, 62, 97-110.

Smith, P. B., \& Peterson, M. (1988). Leadership, organizations, and culture. Beverly Hills, CA: Sage. 
Ting -Toomey, S. (1985). Toward a theory of conflict and culture. In W. B. Gudykunst, L.P. Stewart, \& S. Ting-Toomey (Eds.), Communication, culture, and organizational processes (pp. 71-86). Beverly Hills, CA: Sage.

Tse, D. K., Francis, J., \& Walls, J. (1994). Cultural differences in conducting intra- and intercultural negotiations: A Sino-Canadian comparison. Journal of International Business Studies, 25, 537-555.

Yukl, G. (1998). Leadership in organizations (4th ed.). Englewood Cliffs, NJ: Prentice Hall.

Yukl, G., \& Falbe, C. M. (1990). Influence tactics in upward, downward, and lateral influence attempts. Journal of Applied Psychology, 75, 132-140.

Yukl, G., Falbe, C. M., \& Youn, J. Y. (1993). Patterns of influence behavior for managers. Group and Organization Management, 18, 5-28.

Yukl, G., Guinan, P. J., \& Sottolano, D. (1995). Influence tactics used for different objectives with subordinates, peers, and superiors. Group \& Organization Management, 20, 272296.

Yukl, G., Kim, H., \& Falbe, C. M. (1996). Antecedents of influence outcomes. Journal of Applied Psychology, 81, 309-317.

Yukl, G., \& Tracey, B. (1992). Consequences of influence tactics used with subordinates, peers, and the boss, Journal of Applied Psychology, 77, 525-535. 